\title{
LECUONA: CORPO E SENSAÇÃO EM MERLEAU-PONTY
}

\section{Thays Anyelle Macedo da SILVA ${ }^{1}$ e Rosie Marie do Nascimento MEDEIROS ${ }^{2}$}

${ }^{1}$ Doutoranda do Programa de Pós-Graduação em Educação/UFRN; E-mail: thays.macedo@hotmail.com.br

${ }^{2}$ Professora do Programa de Pós-Graduação em Educação Física/UFRN; E-mail:marie.medeiros@gmail.com

Artigo submetido em fevereiro/2015 e aceito em abril/2015

DOI: 10.15628/dialektike.2015.2839

\section{RESUMO}

Nesta pesquisa, convidamos a uma reflexão fenomenológica sobre corpo e sensação em MerleauPonty. Como possibilidade de leitura, escolhemos a obra "Lecuona" da Companhia de Dança Grupo Corpo. Pretende-se aproximar tal obra do discurso filosófico, principalmente dando movimento aos pensamentos fenomenológicos de Maurice Merleau-Ponty, em especial sua tese do sensível e os conhecimentos do corpo, posto que aberturas no conhecimento de modo geral, e na Filosofia moderna especificamente, permitiram, no cenário epistemológico contemporâneo, pensar-se o corpo fenomenal, atravessado por emoções, portanto estesiológico, que permite operações e expressão. Diante disso, recorremos à atitude fenomenológica de Maurice Merleau-Ponty como percurso metodológico, já que em seus estudos o filósofo lança um olhar expressivo sobre o corpo, configurando uma linguagem sensível que é expressa nos movimentos, onde aprofunda as teses da Fenomenologia num novo arranjo para o conhecimento enquanto resultado de nossa experiência no mundo vivido. As reflexões apresentadas nesta pesquisa pretendem levar-nos ao espanto, ao qual muitos desafios se impõem, entre eles a compreensão do corpo e do conhecimento sensível.

PALAVRAS-CHAVE: Corpo; sensação; Merleau-Ponty; Estesiologia; Fenomenologia.

\section{LECUONA: BODY AND SENSATION IN MERLEAU-PONTY}

\begin{abstract}
In this research, we invite a phenomenological reflection on body and sensation in Merleau-Ponty. As a reading possibility, we choose the work "Lecuona" by Companhia de Dança Grupo Corpo. It is intended to approach such work to philosophical discourse, mainly giving relevance to Maurice MerleauPonty's phenomenological thoughts, especially his argument of the sensitive and knowledge of the body. In addition, as there are gaps in knowledge generally and specifically in modern philosophy and they allowed in the contemporary epistemological scenario to think about the phenomenal body, crossed by emotions, so
\end{abstract}

belonging itself to esthesiology, allowing operations and expression. Thus, we resort to Maurice MerleauPonty's phenomenological attitude as a methodological approach, because in his study the philosopher launches an expressive look on the body, setting a sensitive language, which is expressed in the movements, deepening the arguments of the Phenomenology in a new arrangement to knowledge because of our experience in the lived world. The ideas presented in this research intend to carry us to fright, to which many challenges are imposed including the understanding of the body and sensitive knowledge.

KEYWORDS: Body; Feeling; Merleau-Ponty; Esthesiology; Phenomenology . 


\section{PRIMEIRO MOVIMENTO}

Este artigo faz linha com pesquisas que contribuem com a reflexão que amplia a racionalidade em favor de uma realidade corpórea, de um conhecimento sensível, onde o fenômeno de significação não se aparta do corpo e da existência, mas surge da experiência do corpo: no gesto, na palavra dita, no desejo, nas relações afetivas, na dor, nos silêncios, como entrelaçamento ou nós de sentidos.

A noção de sensível desta pesquisa ultrapassa a compreensão de uma qualidade do objeto ou impressão física, mas também como sentido, intenção, significação, desafiando uma lógica objetiva e abrindo a possibilidade de um conhecimento mais flexível com as disparidades dos acontecimentos e com o humano. O sensível é o ser que nos atinge no que temos de mais secreto, em estado bruto ou selvagem, num absoluto de presença do outro e do mundo, afirma MerleauPonty (2004b). Ou seja, este enfatiza o sentido do corpo e do sensível como realidade essencial do humano. Fundamentamo-nos na atitude do filósofo francês Maurice Merleau-Ponty quando afirma o diálogo da filosofia com o mundo de toda gente (Merleau-Ponty, 1991). Expressão que se refere à necessidade de a filosofia dialogar com a cultura, com a experiência vivida, com a história e com as outras formas de produção do conhecimento, como a ciência e a arte (NÓBREGA, 2010, p. 10).

Segundo o filósofo Merleau-Ponty (1994), se queres entender mais esse corpo, é preciso vivê-lo, experimentar suas nuances. O corpo não é coisa, nem ideia, o corpo é movimento, gesto, linguagem, sensibilidade, desejo, historicidade e expressão criadora. Este pensador busca as verdades do corpo em sua subjetividade, na historicidade, nas estesias das relações afetivas, nos discursos, na linguagem poética, entre outras possibilidades da experiência existencial. Essas atitudes são capazes de conduzir à reflexão como possibilidade de reaprender a ver o mundo, reconvocar a sensibilidade, o poder de expressar e de criar.

Merleau-Ponty (1994) ao introduzir a arte ao seu discurso filosófico, afirma que a arte "fala no silencio dos gestos, com sua imensa capacidade de criar sentidos, de significar e de admitir uma verdade que não se assemelhe as coisas, que não tenha modelo exterior, nem instrumentos de expressão predestinados, e que seja contudo verdade" (Merleau-Ponty, 1994, p. 59).Há uma razão na dança expressada no gesto que é manifestada por sua incrível capacidade de significar, de criar espaços de diversas possibilidades. Nóbrega (2009a, p 19) compartilha tais reflexões ao afirmar que "a arte, a poesia, a pintura, a dança apresentam-se como conhecimentos cuja racionalidade é marcada pela estesia do corpo, nuançando sentidos amplos para a comunicação, a expressão e os atos de significação".

Segundo Lancince e Nóbrega (2010), a dança constitui seu próprio discurso a partir de uma tradição técnica, mas também em referência a um discurso estético, crítico e filosófico. Em consequência, podemos dizer que a dança utiliza um vocabulário próprio à filosofia, observando noções como: corporeidade, carne, sensível, temporalidade e outros, tornando-se possível no trato dos objetivos desta pesquisa.

Nesta inquietação, recorro à arte como espanto (assim como fez Merleau-Ponty), com sua explosão do inteligível para se pensar a filosofia do corpo e do sensível. Com essa atitude, volto meu olhar para dança contemporânea do Grupo Corpo, uma cena específica, buscando subsídios que possam oferecer imagens sensíveis dos conceitos e das reflexões sobre corpo com uma 
compreensão da sensação, numa busca pelo Ser de profundidade como uma das intencionalidades desta pesquisa.

Desse modo, lançamos como questão neste artigo: como podemos visualizar, num enfoque fenomenológico, uma compreensão do corpo e da sensação em Merleau-Ponty num diálogo com a cena de Lecuona?

\section{CENÁRIO DA PESQUISA}

Com a pretensão de encontrar um percurso metodológico que viabilizasse o encontro com os objetivos aqui já mencionados, dirigimo-nos à atitude fenomenológica de Merleau-Ponty que define um olhar expressivo sobre o corpo. Este filósofo configura uma linguagem sensível que é expressa nos movimentos e aprofunda as teses da Fenomenologia num novo arranjo para 0 conhecimento enquanto resultado de nossa experiência no mundo vivido (NÓBREGA, 2009b).

A noção mundo vivido não se refere a uma identificação pessoal, introspectiva, nem num entendimento apenas relacionado ao "meu" mundo e "minhas" relações. Segundo Nóbrega (2010), o vivido não é um sentimento, mas refere-se à percepção como modo original da consciência, ou seja, essa expressão mundo-vivido é uma tentativa de tradução da expressão alemã lebenswelt, que diz respeito ao mundo pré-reflexivo, este que nos possibilita o refletido. 0 termo lebenswelt ganha força com o entendimento sobre a questão da verdade, a partir da obra de Husserl "Investigações Lógicas", reflete-se a verdade não como adequação do pensamento ao objeto, não sendo definida a priori pelo sujeito e nem contemplada na pura exterioridade do objeto. A verdade é definida na evidência da experiência vivida.

Nesse entendimento, a Fenomenologia busca como finalidade compreender o sentido do mundo, ou seja, suas essências. Onde estas essências, encontram-se na existência. Nóbrega (2009) define a fenomenologia como sendo a atitude de envolvimento com o mundo da experiência vivida, com o intuito de compreendê-la. Esta compreensão não é uma representação mental do mundo, mas, sim, envolvimento que permite a reflexão e a interpretação.

Em relação à noção de mundo, Merleau-Ponty (1994) afirma que o mundo é aquilo que vivo e não aquilo que penso. Estamos vulneráveis a este mundo, comunicamo-nos com ele, mas não podemos possuí-lo, pois este é inesgotável. A atitude fenomenológica desta pesquisa ultrapassa o racionalismo ao lançar-se no mundo da arte e, com isso, buscar novos olhares e novos sentidos para a existência, unindo sujeito e o objeto em sua compreensão de mundo e de corpo.

Nesse sentido, destacamos a redução fenomenológica como caminho para busca de novos sentidos e significados relativos ao corpo nesta pesquisa. De acordo com Merleau-Ponty (1994), para apreender, descrever e atribuir sentidos aos acontecimentos é preciso, inicialmente, romper com nossa familiaridade com o mundo- vida, recusar-lhe nossa cumplicidade, colocando-a fora de jogo, para uma melhor compreensão.

É porque somos do começo ao fim relação ao mundo que a única maneira, para nós, de apercebermo-nos disso é suspender este movimento, recusar-Ihe nossa cumplicidade, ou ainda coloca-la fora do jogo (...) a reflexão não retira do mundo em direção à unidade da consciência enquanto fundamento do mundo; ela toma distância para ver brotar as transcendências, ela distende os fios intencionais que nos ligam ao mundo para fazê-lo aparecer, ela só é consciência do mundo porque o revela como estranho e paradoxal (MERLEAU-PONTY, 1994, p.10) 
Essa redução nunca será completa, como evidencia o filósofo, pois estamos imbricados no mundo e fazemos parte de sua teia por meio de nossas experiências. A redução começa com o afastamento das nossas crenças e ideologias para, assim, interroga-las e permitir a criação de novos sentidos.

Dando encaminhamento a essa metodologia, apropriamo-nos da técnica de pesquisa Hermenêutica. No que se refere a esses modelos, Nóbrega (2010), ao destacar o círculo hermenêutico, afirma:

O círculo hermenêutico contém, portanto, procedimentos de validação pelos quais testamos nossas conjecturas. Certamente, são procedimentos de outra ordem que não a verificação empírica, dado que consideram outra lógica de construção: métodos dos índices de convergências (probabilidade subjetiva); critério de falseabilidade entre interpretações rivais; construção gramatical do texto (sentido gramatical do texto); contexto da obra, exegese, entre outros. (NÓBREGA, 2010, p. 41)

O círculo hermenêutico nos dará as possibilidades em lançar uma dialética entre explicação e compreensão na teoria da interpretação, no risco de encontrar nos discursos filosóficos e coreológicos desta pesquisa as interconexões e as solidariedades entre ambos, visando com isso à ressignificação das relações corpo e conhecimento.

Segundo Nóbrega (2010), o conhecimento como interpretação exige, não uma correspondência, uma imagem mental do mundo observado, mas a reflexão, por meio do qual é possível atribuir diferentes significados a um mesmo fenômeno.

Nesse sentido, nessa pesquisa, de natureza reflexiva e com suporte na abordagem fenomenológica, buscamos analisar e descrever uma cena do espetáculo Lecuona. Os critérios de escolha dessas cenas basearam-se na percepção das características que nos fizessem refletir sobre um corpo sensível que tece um conhecimento - conhecimento este afirmado em nosso argumento de pesquisa.

\section{LECUONA}

O espetáculo Lecuona foi estreado no ano de 2004, sob direção artística, iluminação e cenário de Paulo Pederneiras; coreografia de Rodrigo Pederneiras e figurino de Freuza Zichemeister.

Vestida de vermelho, entra no palco a bailarina e seu partner ${ }^{1}$ em todo preto de elegância, ao som cubano do Ernesto Lecuona, Te he visto pasar, que dá o tempero apimentado desta dança. Os dois começam a coreografia numa caminhada de costas, um do lado do outro, mas sem toques, vindos da primeira coxia da esquerda de quem aprecia, numa diagonal em direção à última coxia da direita. A caminhada é sedutora e característica, o quadril comanda, dando o toque de sedução na dança e sensualidade aos corpos. No momento que chegam ao meio do palco, dá-se o encontro, marcado pelo entregar-se das mãos e, em seguida, um olhar profundo, num convite ao tango. A partir de então, tocantes-tocados, sentidos-sentientes, não se separam, e em todo entrelaçamento, os corpos vibrantes são entregues à dança, entregues às sensações.

\footnotetext{
${ }^{1} \mathrm{O}$ par da dança.
} 
O Espetáculo é todo um investimento em pares², ressignificações das danças de salão (bolero, tango, valsa). Pode-se dizer deste espetáculo que é a dança da paixão. Amores ardentes, vorazes volúpias, ciúmes nefastos, corações partidos, saudades brutais, desprezo, doçura, rancor, indiferença, múltiplas sensações dançam em Lecuona. São doze casais que dançam, cada um contando uma história de amor diferente, mas que qualquer humano possivelmente já viveuhistórias de sofrimentos, entregas, sacrifícios, arrepios de nuca, lágrimas na dor, de felicidade, de suor e saliva, no salto alto e mocassins pretos. São histórias de dança de salão e ciúme, de abandono e êxtase.

Entre os casais que dançam em Lecuona, temos o que interpreta a música Te he visto pasar, este escolhido nesta pesquisa para apreciarmos e pensarmos. Não que os outros onze não fossem belos com as reflexões em andamento neste artigo, inclusive, cada um mais fascinante e pulsante que o outro, mas, o Te he visto pasar mobiliza mais minhas sensações e sentidos, dá-nos mais possibilidades e uma beleza reveladora para pensarmos juntos com as pulsões desta pesquisa.

Em relação aos gestos desta cena, criam uma dialética do amor, uma reversibilidade entre os corpos que os fazem um só na sensação. Eles traduzem desejo, sedução, sensualidade e mais, sendo possibilidades desses corpos que se lançam um em direção ao outro. Percebo, no ato da dança, certo deixar-se dominar pelo outro. No início da coreografia quem a conduz é o bailarino, nesse momento, a bailarina se deixa com louvor ser conduzida, natural na dança de salão. 0 bailarino conduz o corpo da bailarina como uma marionete, num jogo de aceitação, mas, no decorrer da brincadeira, o jogo se inverte e, logo, quem comanda passa ser comandado. Vemos as ressignificações da dança de salão não só na arquitetura dos passos, mas, também, nesta postura da bailarina em conduzir o bailarino em certo momento da dança. O "quero" das trocas de carícias, dos momentos calientes de amor, é logo precedido do "não te quero mais" da decepção, do abandono, da agressividade sutil percebida nos gestos dos bailarinos e possivelmente reconhecíveis pelos nossos próprios conflitos humanos.

A música do Ernesto Lecuona, ao se unir a esses gestos e ao conjunto da dança, requebra nossas emoções, dá um ritmo às intenções operantes da dança, conta uma história de amor e favorece um espetáculo para nossos sentidos. Com letras que beiram o brega, mas não se distanciam do corpo e nem da condição humana, o romantismo das canções de Ernesto Lecuona (1895-1963) havia capturado o coreógrafo Rodrigo Pederneiras, como podemos perceber em seu relato:

Quando encontrei a música do cubano Ernesto Lecuona, em São Francisco, numa viagem aos Estados Unidos... decidi que iria montá-la. Estava apaixonado pelo disco Ernesto Lecuona...e coloquei a trilha nas mãos do Nando (Fernando Velloso). Entreguei-Ihe o CD com a seguinte recomendação: 'antes de ouvir esse disco, tome duas doses de uísque e fique na penumbra. Você vai chorar muito. (PEDERNEIRAS apud REIS, 2008, p. 108)

Há uma profundidade nesta obra do Grupo Corpo que gostaria de tentar desvelar e sugerir um diálogo que nos permita colocar em suspenso a cena e suas artimanhas artísticas e interrogála, mirando o poder de um corpo sensível que, diferente das "coisas", permite-se, no milagre das sensações, estar com os outros.

\footnotetext{
2 Todo o espetáculo é construído por pares de dança, ou melhor, casais que interpretam em dança cada um em uma cena.
} 


\section{DIÁLOGO FENOMENOLÓGICO SOBRE CORPO E SENSAÇÃO}

Pensamos interessante, para começarmos nosso diálogo filosófico, refletirmos sobre a noção de sensação. Quando se fala em sensação parece óbvio o "eu sinto calor", "eu sinto frio", "eu sinto alegria", "eu sinto tristeza", enfim, parece fácil quando mutilamos da sensação o fenômeno da percepção, quando a resumimos ao pensamento objetivo como o empirismo e o intelectualismo. A sensação não é um estado ou uma qualidade, apenas impressões do objeto ou limitada aos órgãos dos sentidos, como nos explica os conceitos fisiológicos, por um processo estímuloresposta. Ela é mais confusa, complexa e misteriosa, exige um esforço corporal que a ciência clássica tem preguiça de se dispor revelar.

As sensações são compreendidas em movimento, como nos afirma Merleau-Ponty (1994, p. 284): “a cor, antes de ser vista, anuncia-se então pela experiência de uma certa atitude de corpo que só convém a ela e com determinada precisão". A sensação é dada como significação que está atrelada as experiências do corpo e não às qualidades do objeto, ou seja: “... e a sensação é literalmente uma comunhão" (MERLEAU-PONTY, 1994, p. 286).

Nesse entendimento, a sensação está relacionada à ação do corpo. Essa nova compreensão de sensação como atitude corporal modifica a noção de percepção proposta pelo pensamento objetivo que descreve a percepção através de estímulos e órgãos dos sentidos, a partir da causalidade linear estímulo-resposta.

Merleau-Ponty (2004), na expressão da pintura, principalmente na arte de Cézanne, é solidário com essa noção de sensação quando afirma:

Cézanne não acha que deve escolher entre a sensação e o pensamento, assim como entre o caos e a ordem. Não quer separar as coisas fixas que nos aparecem ao olhar de sua maneira fugaz de aparecer, quer pintar a matéria ao tomar forma, a ordem nascendo por uma organização espontânea. (MERLEAU-PONTY, 2004b, p. 306)

Nesta compreensão, a sensação não é o oposto da percepção, posto que na própria sensação há significação que faz compreender a experiência vivida e suas múltiplas possibilidades de significações, mostrando que no sentir há sentido. Em O Visível e o Invisível (2009), com a crítica à fé perceptiva, Merleau-Ponty compreende a percepção como interrogação da realidade, uma percepção ancorada no corpo, não em uma consciência que sobrevoa o corpo e que por processos cognitivos abstratos ordena as ações e o próprio pensamento sem vínculos corporais, mas uma carne que está aqui e agora e por sua reversibilidade funda-se um corpo a outro, criando espaços de significações, como nos afirma Merleau-Ponty (2009) nesta citação logo abaixo:

Assim como há uma reversibilidade daquele que vê e é visto, assim como no ponto em que se cruzam as duas metamorfoses nasce o que se chama de percepções... a significação é o que vem selar, fechar, reunir a multiplicidade dos meios psíquicos, fisiológicos, linguísticos da elocução, contraí-los num ato único, como a visão termina o corpo estesiológico. (MERLEAU-PONTY, 2009, p. 149) 
Este filósofo, num amadurecimento de seu próprio pensamento, não quer mais compreender a sensação ${ }^{3}$, ele quer a sensação, esse êxtase, entregar-se aos sentidos, ele quer a interrogação, o esboço, o ser como inacabamento. $\mathrm{E}$, com isso, instaurar seu pensamento filosófico neste momento de estesia do corpo, nesta vibração da carne. Numa compreensão ecoada nas palavras do artista Cézanne: "o que eu tento traduzir-vos é mais misterioso, incrusta-se nas próprias raízes do Ser, na fonte impalpável das sensações" (CÉZANNE apud MERLEAU-PONTY, 2004, p.11)

Essas noções se fundamentam no sensível. A noção de sensível que esta pesquisa assume entra em coerência com os pensamentos de Maurice Merleau-Ponty. Em " $O$ filósofo $e$ sua sombra" ${ }^{4}$ este filósofo retoma as obras de Husserl, trazendo o impensado de suas obras, especialmente no que se refere o tema da redução, da constituição e da ontologia do ser, elaborando a tese do sensível. O sensível assume um lugar central no pensamento do filósofo Merleau-Ponty, constituindo-se numa noção orientadora para reflexões ontológicas e epistemológicas. O sensível desafia a análise objetiva.

Todo o conhecimento, todo o pensamento objetivo vivem desse fato inaugural que eu senti, que tive, com essa cor ou qualquer que seja o sensível em causa, uma existência singular que tolhia repentinamente o meu olhar, e contudo prometia-lhe uma serie indefinida de experiências, concreções possíveis desde já reais nos lados ocultos da coisa, lapso de duração dado numa só vez. A intencionalidade que liga os momentos da minha exploração, os aspectos da coisa, e as duas séries uma em relação à outra, não é a atividade de ligação do sujeito espiritual, nem as puras conexões do objeto, é a transição que como sujeito carnal efetuo de uma fase do movimento para outra, por princípio sempre possível para mim porque sou esse animal de percepções e de movimentos que se chama corpo. (MERLEAU-PONTY, 1991, p. 184)

O sensível é fundamentado no acontecimento, no vivido, numa sinfonia humana e que como tal é inesperada, manchada e repleta de possibilidades, o que torna bem difícil sua percepção por uma lógica linear, a partir de um causalidade unívoca. É necessária outra lógica, um conhecimento sensível, mais compreensivo e flexível com as disparidades dos acontecimentos e com o humano. O sensível é compreendido não apenas como qualidade do objeto ou impressão física, mas também como sentido, intenção, significação. O sensível é o ser que me atinge no que tenho de mais secreto, em estado bruto ou selvagem, num absoluto de presença do outro e do mundo (MERLEAU-PONTY, 2004).

O sensivel parte da comunicação dos sentidos, este fundamentado pela experiência estética. Ela, como dimensão do sensível, expressa o belo. O belo, não sendo uma ideia ou modelo, precisa ser experimentado, vivido, solicitando, assim, a sensibilidade, como um convite à contemplação, segundo nos afirma Nóbrega:

\footnotetext{
${ }^{3}$ Percebemos que houve um amadurecimento desta noção de sensação no próprio filósofo Merleau-Ponty. No seu livro Fenomenologia da Percepção ainda se vê um querer compreender a sensação, o que não se percebe em suas últimas obras, principalmente em $O$ Visível e o Invisível. Nesta, o filósofo se interessa pelo êxtase, pela vibração que a sensação causa na carne e, com isso, tenta estabelecer sua filosofia neste momento de estesia do corpo.

${ }^{4}$ Artigo contido no Livro Signos (1991).
} 
A experiência estética amplia a operação expressiva do corpo e a percepção, afinando os sentidos, aguçando a sensibilidade, elaborando a linguagem, a expressão e a comunicação. (NÓBREGA, 2010, p 93)

Fundamentada a esses pensamentos, Nóbrega (2010) entende que o sensível não é uma aparência confusa que precisa ser eliminada pela consciência, nem uma simples objetivação da matéria física, mas é a realidade constitutiva do ser e do conhecimento que se manifesta nos processos corporais. O sensível constitui a síntese da percepção e do movimento. Ela expressa a existência humana de forma profunda, com suas incertezas, sua imprevisibilidade e abertura a diferentes interpretações, unindo os conceitos e vivências e criando a possibilidade de novas formas de elaboração do conhecimento.

A fenomenologia do sensível é profundamente marcada pelo encontro do olhar com a significação, processo em que não há separação entre a expressão e o expresso, o ato e a significação, bem expressada na estesia do corpo.

A estesia do corpo é uma noção proposta na fenomenologia de Merleau-Ponty, principalmente refletida nos livros Le Visible et L'Invisible" (1964) e Résumé de Cours - 1952-1960 (1968). Tal estesia expressa o corpo capaz de sensação, aberto ao outro e, diante disso, multiplicador de sentidos.

$\mathrm{Na}$ inspiração da coreografia Te he visto pasar, a estesia se realiza no momento em que lanço o olhar sobre essa obra, olhar nos gestos dos bailarinos, envolvo-me com a música, com o vermelho sangue do vestido da bailarina, envolvo-me com a história de amor do casal, todo este misto convoca minhas memórias, minhas experiências, minhas profundas e misteriosas sensações, penetro com este olhar o visível ao encontro do invisível, sou eles e eles sou eu. Ao mesmo tempo em que olho aqueles corpos dançando, eles me veem, há a metamorfose, há reversibilidade, há sentido no entrelaçamento de um no outro causada pela estesia do momento e pela carne do agora. Este olhar, não aportando ao órgão do olho, mas compreendido como ato de significação, não se separa da estesia, da presença sensível como nos afirma Nóbrega (2009a). Ou mesmo, como nos inspira Merleau-Ponty (2009, p. 135), ao afirmar: "sobretudo, ser visto por ele, existir nele, emigrar para ele, ser seduzido, captado, de sorte que vidente e visível se mutuem reciprocamente e não mais se saiba quem vê e quem é visto".

Segundo Merleau-Ponty (2009), no entrelaçamento possível com o outro dado pela experiência do corpo, as propriedades do objeto e as intenções do sujeito não apenas se misturam, mas constituem um todo novo. Este movimento vivo, necessário e expressivo se estabelece na estesia do corpo através da reversibilidade dos sentidos. Assim, para o irrefletido, para o impensado, parte o movimento da reversibilidade, vai em direção ao mistério do mundo, ou seja, para um novo encanto.

Quando a carne do corpo se propaga à carne do mundo, e a do mundo para a do corpo, nesta reversibilidade, deste entrelaçamento é que nasce a percepção. Concebida pela experiência vivida através do corpo em movimento, a percepção aflora sentidos diversos, o que faz Merleau-Ponty (2009) afirmar que a relação corpo-mundo é estesiológica. Nessa relação, a comunicação entre diferentes corpos ocorre através do jogo dos sentidos. Considerando-se que é a sensorialidade que anima a carne e que abre o corpo para o mundo. É a realidade do corpo que nos permite sentir e, portanto, perceber o mundo, os objetos, as pessoas, e mediante a essas experiências, sonhar, desejar, imaginar, pensar, narrar, conhecer e escolher (NÓBREGA, 2010). 
Segundo Merleau-Ponty (1991), aqueles que mediante a paixão e o desejo chegam até esse Ser de profundidade sabem o que é para saber e a filosofia não os compreende melhor do que eles mesmos se compreenderam, pois eles que vivenciaram, sentiram, amaram e isso é uma verdade expressa na estesia do corpo. É nesta experiência desses atores que a filosofia conhece o Ser. Nóbrega (2010), em sua dedicação aos estudos sobre a noção de estesia em Merleau-Ponty, afirma poeticamente que:

A estesia do corpo proposta na fenomenologia de Merleau-Ponty apoia-se em uma compreensão erótica da vida e do conhecimento que ultrapassa as dicotomias clássicas e o racionalismo. A percepção erótica irá permitir uma forma de compreensão da relação corpo-mundo não da ordem do eu penso, à maneira do cogito cartesiano, mas do eu vivo, eu sinto, eu amo (NÓBREGA, 2010 p. 95).

A estesia do corpo é um milagre da existência proporcionado pela dança dos sentidos; A saudade sempre infinita dos outros. A busca pela mistura, pela dança do entrelaçamento. Poder do corpo como carne, como possibilidade, objeto/sujeito, visível/invisível, simbolismo, enigma, criação e desejo. Todo este misto e mais se urgência no corpo, esta animalidade que nos põe em presença, em contato, em penetração ao outro por uma incrível capacidade de sensação.

No caso da cena descrita de Lecuona, há esta capacidade de sentir por um corpo sensível que anima a carne e convoca às memórias. Encontro, desencontro e reencontro, uma memória que surge dotada de sentido, estesia, dança do amor e rejeição. Há um corpo estesiológico ali carregado de aprendizagens, que ama, que sofre, que escolhe, ressignifica, decide mudar de direção. Quando lanço esse olhar de significações sobre a cena Te he visto pasar percebo os movimentos que muito expressam esta dialética do amor, dos encontros da vida, das experiências existenciais, cheios de alegrias e de dores, de prazeres e de angústias, que ninguém está salvo, nem totalmente perdido.

Nessa dialética do amor que nos sugere este espetáculo, elementos nos são fornecidos para se pensar os conhecimentos do corpo nesse momento de estesia dos encontros. Entendendo como dialética não uma relação entre pensamentos contraditórios e inseparáveis, mas, a tensão de uma existência em direção à outra existência que a nega e sem a qual, todavia, ela não se sustenta, como afirma Merleau-Ponty (1994).

Quando se fala que Lecuona é o balé da paixão, fala-se da paixão no sentido de tudo que me afeta, me agarra, me liga ao outro, da ordem do sensível. Nesta cena de Lecuona podemos perceber o corpo como ser sexuado, a experiência do desejo e dos afetos como estesia, como comunicação sensível, ligada ao corpo, ao mesmo tempo, objeto para o outro e sujeito para mim - vice versa.

Aqui, nesta dança, percebemos a entrega à sensação por corpos que se permitem. Como diz Merleau-Ponty (2009): " temos um corpo, isto é, não um objeto de pensamento permanente, mas uma carne que sofre quando ferida" (MERLEAU-PONTY, 2009 p. 133). Ou seja, sentir é essa realidade do corpo como carne. O corpo estesiológico é este corpo capaz de sentir, que guarda em torno de si a memória, e que inaugura o agora e suas possibilidades de significações.

O vermelho do vestido da bailarina é sensível, vem carregado de significações e pode transportar a mil mundos. A percepção das cores é um exemplo significativo da estesia colocada por Merleau-Ponty (2009), onde o vermelho que não é o mesmo vermelho dos telhados, daquela roupa vermelha das mulheres, da beca dos professores e advogados, ou mantos dos bispos, ou 
mesmo da bandeira da Revolução. Vermelho que é tirado do fundo das idealidades, que pulsa, que é signo e significação. Da ordem nos dada por Paul Claudel, quando este expressa: "o azul do mar é tão azul que só o vermelho do sangue é mais vermelho". Vermelho que cresce em mim, vermelho que me anima, que me transporta, vermelho que me faz presença, que me incendeia de sensações e sentidos.

O ser visível é natural, construído em torno do ser natural, mas não é possível que nos fundemos nele e nem que ele penetre em nós, no entanto, apalpando-o com o olhar, nós o desnudamos e o envolvemos, o vestimos com nossa carne e o ser invisível ali se torna visibilidade, dotado de significações, dá e recebe sensação (MERLEAU-PONTY, 2009). O vermelho desta dança se torna um campo aberto de significados, eu o visto com minha carne, torna-se vivo e nos convida a colecionar sentidos e significados.

Segundo Merleau-Ponty (1994), "a apreensão das significações se faz pelo corpo: aprender a ver as coisas é adquirir um certo estilo de visão, um novo uso do corpo próprio, é enriquecer e reorganizar o esquema corporal" (MERLEAU-PONTY, 1994, p. 212).

Suas paisagens se cruzam, suas ações e suas paixões se ajustam exatamente, isto é possível desde que parem de definir primordialmente o sentir pela pertencença à mesma 'consciência', compreendendo-o ao contrário, como retorno sobre si no visível, aderência carnal do sentiente ao sentido e do sentido ao sentiente" (MERLEAU-PONTY, 2009, p. 138)

Voltando as significações da cena, percebo que as diferenças que os seduziam no início, os levam às repulsões, a um desprezo e, posteriormente, e de forma inesperada, novas e repetidas atrações, todo esse paradoxo de sensações, tais fragilidades e complicações humanas, permitem a vivacidade da cena, a vibração que acontece quando dois corpos desejantes se encontram num tempero de sexualidade.

Para Merleau-Ponty “o sexual é nossa maneira carnal, já que somos carne, de viver a relação com o outro" (MERLEAU-PONTY, 1991, p. 260). A sexualidade parte da noção para além do físico, de localidade dos órgãos genitais, e mesmo do ato sexual, ou seja, é da ordem da relação e necessidade do outro, vem de uma noção de erotismo que está embasado na tese do sensível em Merleau-Ponty, ou seja: "no momento em que a cor e a carne começam a falar aos olhos e ao corpo" (MERLEAU-PONTY, 1991, p. 261). Temos um corpo sexual sempre em direção a outro, que se deixa ser objeto para esse outro, mas que sente e, diante disso, é sujeito e objeto ao mesmo tempo. E há prazer e dor nisso e está neste movimento as duas faces do risco: que nas pulsões da vida pode vir os muitos absurdos, mas também nossas seguras realizações (MERLEAU-PONTY, 1991).

A experiência estesiológica nos dá o risco, somos entregues a boas ou más sensações compartilhadas, a vários pontos de vistas, novos e inesperados significados. Isso não deixa de ser um milagre, uma realidade que nos diferencia das máquinas, das coisas, e nos permite questionar, criar, escolher, e só acontece quando um corpo vai em direção ao outro e o incorpora. A literatura de Jean Paulhan, ao ser citado por Merleau-Ponty (1991), convida-nos a esse sentido: "nesse instante, pelo menos, eu fui tu" (JEAN PAULHAN apud MERLEAU-PONTY, 1991).

A dialética do amor da cena Te he visto pasar, esse "vai e vem", essa angústia de o "ser para si" e do "ser para o outro" lembra-nos o amor de Proust citado por Merleau-Ponty (1991). Onde pela mesma encarnação, à sua situação própria, capaz de sentir a falta e a necessidade do outro, 
mas incapaz de encontrar no outro o repouso- e surge o "vai e vem" do trágico amor de Proust- e a dor e o prazer deste jogo que nos sustenta.

Segundo este filósofo (2009), ninguém foi tão longe do que Proust ao fixar a relação do visível e o invisível, numa descrição de ideia que não é o contrário do sensível, mas que é seu dúplice e sua profundidade.

Nos movimentos dos bailarinos desta cena descrita, transportamo-nos a este mundo de relações, de encontros que nos une ao outro e gera sensações diversas, experiências, e existe logus nisso, como afirma Merleau-Ponty (2009): "o que vivo é tão 'consciente', tão 'explícito' quanto um pensamento positivo" (MERLEAU-PONTY, 2009, p. 146), pois é a experiência da carne vivenciada no corpo e neste agora, é o que vivo e, isso, é uma verdade tão explícita quanto qualquer pensamento positivo.

A dança desses dois bailarinos da cena Te he visto pasar" tem verdade, tem conhecimento, tem solidariedade com as possibilidades humanas, percebo uma empatia entre eles que me obrigam a me envolver na cena e sentir, tem o vivido, o prazer e a dor dos encontros e desencontros que a relação com o outro nos proporciona, uma forma de ser e estar no mundo. A dança de salão em si já é uma dança sugestiva, pois precisa do outro, do entrelaçamento, do ir e vir, da entrega dos corpos. É ali o envolvimento de dois corpos, uma mistura que traz experiência e conhecimento vivido.

O sentir não pede arrependimento, mas experiência, novas formas de solidariedade, aprendizado, mesmo que compartilhando uma dor, esta condição que também faz parte da existência que é por tantas vezes negada por discursos modernos que discriminam do corpo a dor e o sofrimento. Merleau-Ponty (1991, p. 75) nos auxilia nesse reflexão ao afirmar que: "porquanto, agir ou mesmo viver já é aceitar o risco de infâmia com a chance de glória". A vida e o corpo presente no mundo exigem esse sentir que é um milagre do humano.

pretendo-me senhor não só das minhas intenções, mas também daquilo que as coisas farão delas, assumo o mundo, os outros como são, assumo-me a mim mesmo como sou e fortaleço-me com tudo isso (MERLEAU-PONTY, 1991, p. 75)

Por mais que a história de amor dessa dança de Lecuona nos mostre os afastamentos desses corpos como possibilidade, as memórias desses encontros estão no corpo, há um inscrito ali que não pode desaparecer, mas, nem tudo está perdido, pois esses inscritos podem ser ressignificados por novas escolhas, uma nova sensação, como poder do corpo, como nos ensina Merleau-Ponty (1999).

No próprio instante em que vivo no mundo, em que me dedico aos meus projetos, a minhas ocupações, a meus amigos, a minhas recordações, posso fechar os olhos, estirar-me, escutar meu sangue que pulsa em meus ouvidos, fundir-me a um prazer ou a uma dor, encerrar-me nesta vida anônima que subtende minha vida pessoal. Mas, justamente porque pode fechar-se ao mundo, meu corpo é também aquilo que me abre ao mundo e nele me põe em situação. $O$ movimento da existência em direção ao outro, em direção ao futuro, em direção ao mundo pode recomeçar, assim como um rio degela. (MERLEAU- PONTY, 1999, p. 228)

O corpo, a estesiologia, emerge da vida e do desejo. Não pensando esta estesiologia como um pensamento que desce num corpo, sem vínculos corporais. O segredo deste pensamento que Merleau-Ponty interroga está nos acontecimentos e na ligação entre as coisas e profundidade de 
sua expressão. Eu posso por meio da motricidade sentir estesia, este sentido está na presença, no corpo (NÓBREGA, 2010). Vibração do corpo no movimento, no presente, atado ao corpo e aos sentidos. Todos os sentidos misturados. Não "Em si", mas tudo isso. Entrelaçamento do movimento e percepção, graças ao corpo como sensível-exemplar e estesiológico.

A Estesiologia (ciência dos sentidos) pode ser estendida e compreendida como elementos de criação e de compreensão de processos estéticos no domínio da arte em geral (LACINCE; NÓBREGA, 2010). Podemos visualizar investimento na sensorialidade em Lecuona, e especificamente nesta cena, quando vemos nos gestos a ultrapassagem dos códigos instituídos do tango e da própria técnica clássica em prol de uma sensibilidade que agarra a cena, agarra-me.

Entre outras questões, a estesiologia abre o meu corpo para o exterior, incorporação, um corpo poroso com orifícios e passagens, que é também a indivisão do meu corpo e dos outros corpos (NÓBREGA, 2010).

O coreógrafo Rodrigo Pederneiras, investe na sensação nesta dada cena descrita, descrevendo-a como uma forma "violenta", este diz: "Lecuona representou uma mudança de rota que nos trouxe um prazer raro. Toda emotividade da música, os exageros das letras, o falar de sensações de forma tão violenta" (PEDERNEIRAS apud REIS, 2008, p. 108). Esta violência, em meu entendimento, tem haver com o espanto que Lecuona traz ao despertar para sensações em solidariedade com a condição humana, distanciando-se das narrativas clássicas que predominam em seus romances a ideia de "felizes para sempre".

A mudança de rota que o coreógrafo fala neste trecho acima se refere também à música, que não foi composta especialmente para o espetáculo, e também o risco de investir em uma dança só de duos, algo completamente novo ao Grupo que queria mostrar em cada duo formas diferentes de interpretar as paixões.

Em uma entrevista a um site cultural ${ }^{5}$ do governo do Rio de Janeiro, Rodrigo Pederneiras descreve sua percepção sobre o espetáculo: “... Lecuona o que pega é a emoção. Ele bate direto no peito de todo mundo... São situações de amor, ciúme, vingança, paixões perdidas. A plateia ora cai na gargalhada, ora beira as lágrimas" (PEDERNEIRAS, 2004).

Tais reações que este espetáculo causa na plateia mostra o quanto ele é solidário com o humano, desperta a sensibilidade por falar uma linguagem próxima da realidade, negando uma abstração.

Assim, percebo que o corpo que dança em Lecuona é um corpo estesiológico, afetuoso, aberto às surpresas, capaz de afetividade, sexual, orgânico, capaz de sofrer, sentir dor, sentir glórias, sentir bruscas, doces e desconhecidas sensações, mas que continua nesta busca do outro para interrogar sua existência. Esta carne como capaz de sensação, como sensível sesciente, como aparece na vida? A estesia é, se não localizada, pelo menos não é independente da localidade. A estesiologia não está na minha cabeça ou no meu corpo e muito menos em outro lugar. Ela é percebida num espaço de liberdade, de relação. Surge por um investimento na vida. Por acontecimento, por estes encontros e envolvimento dos corpos. Ou seja, "a estesiologia é esta união da alma e do corpo levada a sério" (MERLEAU-PONTY, 2006, p. 360). Ela é esta capacidade do corpo que ao ver as cenas de Lecuona em ação da vontade de "topar na hora", de concordar latinamente "e-u t-e a-m-o", de chorar contigo, comigo, com o que estiver pela frente. O que

\footnotetext{
5 KRAPP, Juliana. O número da sorte do Grupo Corpo. Site Cultura.RJ, 2010. Disponível em: http://www.cultura.rj.gov.br/materias/o-número-da-sorte-do-grupo-corpo
} 
Lecuona do Grupo Corpo nos mostra é que inventamos um grande modo de viver o amor, de concordar com a condição sublime e terrível de sermos humanos que pensam, logo amam, logo existem, logo são corpos. De lidar com o que é complexo de forma complexa. De complicar as coisas ao ponto da harmonia. Lecuona convida a viver para sofrer e amar. É preciso viver. Porque a gente "topa tudo na hora". A gente tem sangue quente. O sangue jorra e tudo bem, a gente chora e tudo vem. O que é quente é preciso. É preciso viver para os próximos corpos que vão topar com a gente. E nestes acontecimentos percebemos a sinergia da razão e o sensível. E Maffesoli (2005) saúda nossas reflexões ao afirmar que:

Assim se exprime a sinergia da razão e do sensível. o afeto, o emocional, o afetual, coisas que são da ordem da paixão, não estão mais separados em um domínio à parte, bem confinados na esfera da vida privada; não são mais unicamente explicáveis a partir de categorias psicológicas, mas vão tornar-se alavancas metodológicas que podem servir à reflexão epistemológica, e são plenamente operatórias para explicar os múltiplos fenômenos sociais, que, sem isso, permanecem totalmente incompreensíveis. Em outras palavras, é preciso fazer de uma fraqueza uma força inegável. (MAFFESOLI, 2005, p. 53)

O que é tido pelo pensamento objetivo como uma fraqueza, a paixão, os afetos, as sensações, nada mais é que uma força que liga os acontecimentos e nos dá o caminho para se compreender os múltiplos fenômenos sociais e permitir construir um pensamento mais orgânico e mais perto do mundo, que, sem esta disposição sensível, não passaria de mera abstração.

Lecuona está longe da abstração, está perto do mundo, está nos acontecimentos, numa inconformidade com o perfeito, com o absoluto, inaugura a possibilidade do sentir como experiência e conhecimento.

\section{DISCUSSÕES}

A narrativa fenomenológica apresentada nesta pesquisa possibilita um olhar sobre o corpo e a sensação, mediante conceitos não cristalizados, mas abertos, principalmente pela influência fenomenológica do filósofo Maurice Merleau-Ponty, com seu olhar diferenciado sobre o corpo sensível, aonde, com o espanto de sua filosofia, aproxima-a do mundo e da condição humana. Assim, foi possível presenciar nas descrições, dando movimento a estes pensamentos, um corpo problematizador do controle, sujeito e objeto inseparáveis, que ao mesmo tempo em que toca é tocado, que sente e é sentido, deseja e é desejado, atravessado por sensações, portanto, estesiológico, que permite criação e expressão.

$\mathrm{Na}$ capacidade estesiológica do corpo, várias possibilidades são oferecidas, entre elas, o poder sentir, compartilhar, mas, também, o poder se envolver, desejar, imaginar, escolher, (re)descobrir e criar. E, mediante a tais merecimentos do corpo como sensível-exemplar, percebese aberturas no pensamento de encontro com a fecundidade da razão, a qual é fruto desse movimento esta pesquisa.

A razão, assim entendida, toma-se não como explicação e, sim, como interrogação interminável, razão alargada, abandonando a ilusão da subjetividade pura e de seu outro lado, a objetividade pura, construída pelas operações de um pensamento que se julga desencarnado (CHAUÍ, 2008). 
Tais saberes sobre o corpo são convocados no cenário epistemológico contemporâneo pela necessidade de ampliar a racionalidade e permitir à ciência "descer à terra", como afirma MerleauPonty (1990, p.43), e estar em contato com o mundo e seus desafios. Esta ligação só seria possível através do corpo e, com isso, de reuni-lo com o que antes foi tirado dele: a razão. Estamos diante de um conhecimento sensível, um pensamento aberto, que vem repercutir uma relação ambígua de um ser encarnado e limitado com um mundo enigmático que ele habita e que só se Ihe é mostrado por meio de perspectivas, que lhe escondem tanto quanto lhe revelam, como afirma Merleau-Ponty (2004a).

O que está em jogo, digamos, é o mistério de nossa existência, de nossa relação com o mundo que vem preceder a todo pensamento "sobre" o mundo. É, mais propriamente, esse nível de experiência que a teoria da carne, no pensamento de Merleau-Ponty busca expressar, enquanto mistério fundamental.

Segundo Nóbrega (2010), por meio do logos estético, sensível, coloca-se a experiência perceptiva como campo de possibilidades para o conhecimento, este flexível e inesgotável. Mas, torna-se necessário entender que o corpo capaz de sensação, apesar de possibilitar à experiência estética, pode ir além, ou seja, a estesia leva-nos pelo caminho da beleza a ultrapassar o "agora" e algo se transforma, diante as possibilidades, somamos sentidos e significados, há movimento e criação, um logos estético se institui. Logo, não somos os mesmos depois de nos banharmos na experiência estesiológica, que entendo nesta pesquisa como a dança da carne, uma capacidade de arte e de pensamento, uma atitude do corpo. Como nos auxilia nessa reflexão Merleau-Ponty (2009)

\begin{abstract}
A literatura, a música, as paixões, mas também a experiência do mundo visível são tanto quanto a ciência de Lavoisier e de Ampère, a exploração de um invisível, consistindo ambas no desvendamento de um universo de ideias. Simplesmente, aquele invisível, aquelas ideias não se deixam separar, como a dos cientistas, das aparências sensíveis, mas erigem-se numa segunda positividade. (MERLEAUPONTY, 2009, p. 144)
\end{abstract}

Assim, muitos desafios se impõem nas experiências sensíveis descritas aqui, entre elas, de aliar o inteligível e o sensível, o entendimento e as sensações numa compreensão do corpo. Temos, assim, uma razão sensível complexa, difícil de arbitrar, mas, mais coerente com os tumultos das ordens humanas. O que entendo, referente a isso, é que ao se arriscar neste conhecimento sensível, neste alargamento de uma razão, não é possível esgotar as possibilidades dessas compreensões, apenas tentar nos aproximar e acariciá-las.

Em Lecuona (2004), temos uma expressão de estesia na experiência do desejo e dos afetos, uma comunicação sensível, denunciando o corpo sexual, avivado pelas paixões, orgânico, capaz de sofrer, sentir dor e sentir glórias, sentir absurdas e desconhecidas sensações, mas que continua nesta busca do outro para interrogar sua existência.

A possibilidade do conhecimento sensível assume o fato de que nem tudo pode ser compreendido, pois há sempre lacunas, mas necessariamente precisa ser vivido pra adquirir sentido. $O$ entendimento do corpo de sensação, que diz respeito à configuração plástica e poética do corpo, realça a procura por novas formas de compreender o mundo, indo, além do racionalismo por uma condição estesiológica. 
Nesta relação corpo e alma, que ultrapassam o campo do visível ao se encontrar com os símbolos, com o imaginário, com a história, com a sexualidade, entre outras formas de gestão da vida e do conhecimento, foi possível, neste ensaio fenomenológico interrogar este corpo estesiológico que é capaz de sensação e diante disso de significar para além do determinado, de criar e recriar sentidos na atmosfera da existência como nos inspira o exercício da filosofia de Merleau-Ponty.

\section{REFERÊNCIAS}

CHAUÍ, Marilena. Merleau-Ponty: a obra fecunda. Revista Cult. n. 123- Ano 11, São Paulo, abril/2008.

LACINCE, N.; NÓBREGA, T. P. Corpo, dança e criação: conceitos em movimento, Revista Movimento, Porto Alegre, v. 16, n. 03, p. 241-258, julho/setembro de 2010.

MAFFESOLI, Michel. Elogio da razão sensível. Petrópolis: Vozes, 2005.

MERLEAU-PONTY, Maurice. Os Pensadores. São Paulo, Abril cultural, 1975.

. Signos. São Paulo: Martins Fontes, 1991.

O Visível e o Invisível. São Paulo; Perspectiva, 4ạ edição. 2009.

Le Visible et L’Invisible. Paris: Gallimard, 1964.

. Fenomenologia da Percepção. São Paulo. Martins fontes, 1994.

. Conversas. São Paulo. Martins Fontes, 2004 a.

. Olho e o Espírito. São Paulo. Cosac e Naify, 2004b.

. A Natureza: curso do Collège de France. São Paulo; Martins Fontes. 2006.

. Résumés de cours : Collège de France 1952-1960. Paris: Gallimard, 1968.

NÓBREGA, Terezinha Petrucia. Uma Fenomenologia do Corpo. São Paulo: Editora Livraria da Física, 2010. RN, 2011.

Merleau-Ponty: movimento do corpo e do pensamento, Revista Vivência, n. 36, p. 127-136, Natal2009a.

(org.). Escritos sobre o corpo: diálogo entre arte, ciência, filosofia e educação. Natal: EDUFRN,

. Corporeidade e Educação Física: do corpo-objeto ao corpo-sujeito. Natal: EDUFRN. 2009b.

REIS, Sérgio Rodrigo. Rodrigo Pederneiras e o Grupo Corpo: dança universal. São Paulo: Imprensa Oficial, 2008. 